\title{
Expansile Endocervical Crypt Involvement by CIN2-3 as a Risk Factor for High Grade Cytology Recurrence After Cold Coagulation Cervical Treatment
}

\author{
Ausgedehnte CIN II-III in den endozervikalen Krypten \\ als Risikofaktor für ein hochgradiges zytologisches Rezidiv \\ nach kalter Koagulation
}

\section{(ㄷ)(i) (오 $\ominus$}

Authors

Dimitrios Papoutsis ${ }^{1,2}$, Martyn Underwood ${ }^{1}$, Joanna Williams ${ }^{3}$, William Parry-Smith ${ }^{1}$, Jane Panikkar ${ }^{1}$

Affiliations

1 Department of Obstetrics and Gynaecology, Shrewsbury and Telford Hospitals NHS Trust, Telford, United Kingdom

2 Department of Health Sciences, University of Western Macedonia, Koila, Kozani, Greece

3 Department of Histopathology, Shrewsbury and Telford Hospitals NHS Trust, Telford, United Kingdom

Key words cold coagulation, endocervical crypt involvement, cytology recurrence, $\mathrm{CIN}$

Schlüsselwörter

kalte Koagulation, Befall der endozervikalen Krypten, zytologisches Rezidiv, CIN

received 28.12.2019

revised 24.4.2020

accepted 17.6.2020

Bibliography

DOI https://doi.org/10.1055/a-1202-2157

Geburtsh Frauenheilk 2020; 80: 941-948 @ Georg Thieme

Verlag KG Stuttgart · New York | ISSN 0016-5751

Correspondence

Dimitrios Papoutsis

Shrewsbury and Telford Hospitals NHS Trust

Apley Castle, Grainger Drive, Telford, TF1 6TF, United Kingdom dimitrios.papoutsis@nhs.net

\section{ABSTRACT}

Introduction To determine whether expansile endocervical crypt involvement (ECI) on pretreatment cervical punch biopsies is a risk factor for high grade cytology recurrence in women following cold coagulation for cervical intraepithelial neoplasia (CIN).
Materials and Methods This was a secondary analysis on the results of an observational study of women who had a single cold coagulation cervical treatment between 2001-2011 and who were followed up for cytology recurrence. Women with a previous cervical treatment were excluded.

Results 559 women were identified with a mean age of $28.7 \pm 6.2$ years. Expansile and non-expansile ECI were identified in 5.4 and $4.3 \%$ of women, respectively. The proportion of women with high grade cytology recurrence was $10 \%$ for those with expansile ECI and 2.3\% for those without. Multivariate analysis showed that women with expansile $\mathrm{ECI}$ when compared to those without, had a four-fold greater risk for high grade cytology recurrence $(\mathrm{HR}=4.22 ; 95 \% \mathrm{Cl}: 1.10-$ $16.29, p=0.036)$. There was no significant association found between non-expansile $\mathrm{ECl}$ and overall or high grade cytology recurrence. The increased biopsy depth and the CIN3 grade of pretreatment cervical punch biopsies were significantly associated with greater odds for the detection of expansile ECI. We calculated that the optimal-cut off of pretreatment cervical punch biopsy depth for the detection of expansile ECI was 4 mm (sensitivity: $73.3 \%$; specificity: $55.1 \%$ ).

Conclusions Expansile $\mathrm{ECl}$ is a risk factor that increases the likelihood of high grade cytology recurrence following cold coagulation. Deeper pretreatment cervical punch biopsies need to be taken so as not to miss expansile ECI prior to ablative treatment.

\section{ZUSAMMENFASSUNG}

Einleitung Ziel dieser Studie war es, herauszufinden, ob ein bei der Stanzbiopsie ermittelter ausgedehnter Befall der endozervikalen Krypten (endocervical crypt involvement, ECI) einen Risikofaktor für ein hochgradiges zytologisches Rezidiv bei Frauen darstellt, die mit kalter Koagulation zur Behandlung zervikaler intraepithelialen Neoplasien (CIN) therapiert wurden.

Material und Methoden Es handelt sich hierbei um eine sekundäre Analyse einer Observationsstudie von Frauen, die 
sich zwischen 2001-2011 einer Zervixbehandlung mit kalter Koagulation unterzogen und anschließend regelmäßig zur zytologischen Nachkontrolle einbestellt wurden. Frauen, die sich zuvor einer Zervixbehandlung unterzogen hatten, wurden von der Studie ausgeschlossen.

Ergebnisse Insgesamt wurden 559 Frauen identifiziert, mit einem mittleren Alter von 28,7 $\pm 6,2$ Jahren. Bei 5,4 bzw. 4,3\% dieser Frauen wurde ein ausgedehntes resp. nicht ausgedehntes ECl festgestellt. Der Anteil Frauen mit hochgradigen zytologischen Rezidive betrug 10\% bei den Frauen mit ausgedehntem Befall und 2,3\% bei denen ohne ausgedehnten Befall. Bei der multivariaten Analyse stellte sich heraus, dass Frauen mit einem ausgedehnten zervikalen Befall ein 4-fach höheres Risiko für ein hochgradiges zytologisches Rezidiv hatten als Frauen ohne ausgedehnten Befall ( $H R=4,22$; 95\%-KI 1,10-16,29; $p=0,036)$. Es gab keinen signifikanten Zusammenhang zwischen nicht ausgedehntem Befall und einem allgemeinen bzw. hochgradigen zytologischen Rezidiv. Biopsietiefe und ein CIN-III-Befund bei der zervikalen Stanzbiopsie vor der Behandlung waren signifikant mit einer höheren Wahrscheinlichkeit eines ausgedehnten ECl assoziiert. Nach unseren Berechnungen betrug die optimale Tiefe für zervikale Stanzbiopsien zur Entdeckung eines ausgedehnten ECl 4 mm (Sensitivität: 73,3\%; Spezifizität: 55,1\%).

Schlussfolgerungen Ein ausgedehntes $\mathrm{ECl}$ stellt einen Risikofaktor dar, der die Wahrscheinlichkeit eines hochgradigen zytologischen Rezidivs nach kalter Koagulation erhöht. Es empfiehlt sich, tiefere zervikale Biopsien zu nehmen, um sicherzustellen, dass ausgedehnte $\mathrm{ECI}$ vor der ablativen Behandlung entdeckt werden.

\section{Introduction}

Cold coagulation is a form of thermal ablation in the treatment of cervical cancer precursor lesions and was first introduced by Semm in 1996 [1]. After an initial decrease in its acceptance due to the widespread use of excisional techniques [2], cold coagulation has once again gained popularity due to the growing literature evidence of its feasibility, acceptability, safety and efficacy in treating cervical intraepithelial neoplasia (CIN) [3-5]. The systematic review and meta-analysis of Dolman et al. in 2014 that included 13 studies involving 4569 women treated with cold coagulation for CIN, showed a cytology cure rate of approximately $95 \%$ for CIN2+ lesions [4]. An updated review and meta-analysis of Randall et al. in 2018 included 23 studies involving 6371 women that were treated with cold coagulation for biopsy proven CIN2+ lesions, and demonstrated a cytology cure rate of $93.8 \%$ which is comparable to other excisional and ablative methods $[4,5]$. There are literature reports that cold coagulation when compared to large loop excision of the transformation zone (LLETZ) has comparable cytology and virological cure rates after treatment $[3,6]$. Other studies have shown that cold coagulation when compared to LLETZ cervical treatment seems to be more "cervix friendly" with regards to adverse pregnancy outcomes in future pregnancies as it is associated with a less spontaneous preterm birth and miscarriage rate [7].

Despite the growing body of evidence about the advantages of cold coagulation in treating $\mathrm{CIN}$, nevertheless there are only few reports on the risk factors for cytology recurrence after ablative cervical treatment. Parity $\geq 2$ and endocervical crypt involvement (ECI) by $\mathrm{CIN}$ on pretreatment cervical punch biopsy have been shown to be risk factors for cytology recurrence after cold coagulation [8]. In addition, for women treated with excisional cervical treatment it has been demonstrated that $\mathrm{ECI}$ on the cervical excision specimen represents a risk factor for disease recurrence [913]. The explanations that have been given are that crypt involvement by CIN may represent a deeper or multifocal lesion with a more aggressive potential of CIN associated with high-risk human papilloma virus (HPV) strains.
The National Health Service Cervical Screening Programme (NHS-CSP) guidelines report that extensive involvement of the endocervical glands represents a variant of CIN3 that is more likely than others to be associated with early invasion and they require that the presence of crypt involvement by CIN always be reported in the histopathology report [14]. The same guideline also states that when there is extensive involvement and expansion of the underlying endocervical crypts then the term expansile CIN3 should be used. In this case there is often central necrosis within the glands replaced by CIN3, and intraepithelial squamous maturation may also be observed [14].

The main goal of this study was to perform a secondary analysis on the results of a previously published study in 2015 from our research team where endocervical crypt involvement by CIN on pretreatment cervical punch biopsy was identified as a risk factor for abnormal cytology after cold coagulation treatment [8]. In this secondary analysis, we have further examined our original cervical tissue histopathology slides from the pretreatment cervical punch biopsies and we have classified $\mathrm{ECl}$ into expansile and non-expansile crypt involvement by CIN. The primary objective of the current study was to investigate whether expansile crypt involvement increases the likelihood for high grade cytology recurrence after cold coagulation treatment.

\section{Material and Method}

\section{Study population-data collection}

This was a secondary analysis on the findings of an observational cohort study of women treated with cold coagulation ablative treatment at the Shrewsbury and Telford Hospital (SaTH) NHS Trust, between January 2001 and December 2011 [8]. Women with a single cold coagulation treatment were included for the analyses. Women with previous cervical excision or ablation and with no cytology follow-up data were excluded from the study.

We defined overall cytology recurrence as the occurrence of an abnormal cytology test (mild/moderate/severe dyskaryosis) at follow-up after cold coagulation. High-grade cytology recurrence was defined as the presence of moderate or severe dyskaryosis on 

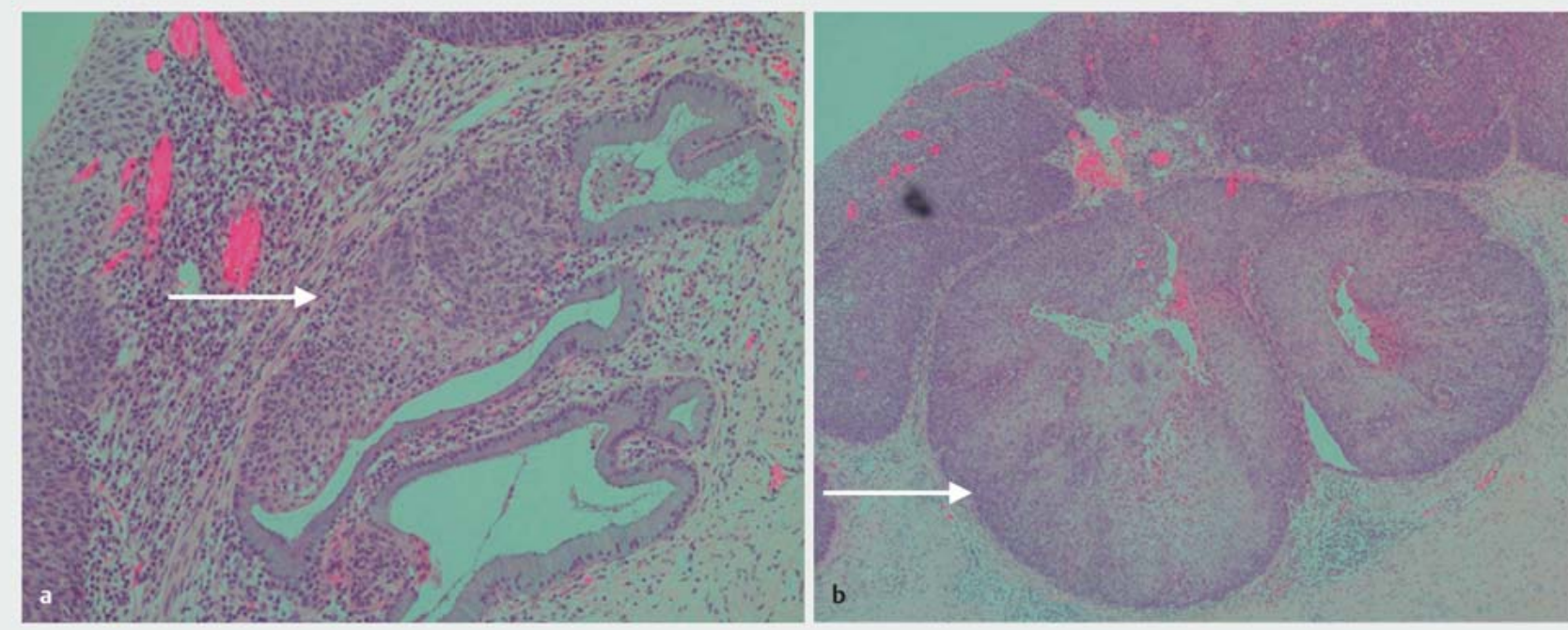

- Fig. 1 Endocervical crypt involvement by CIN3, showing non-expansile (a) and expansile (b) crypt involvement. a In non-expansile crypt involvement by $\mathrm{CIN} 3$, the crypt (white arrow) retains the normal outline ( $\times 10$ magnification, $\mathrm{H} \& \mathrm{E}$ staining). $\mathrm{b}$ In expansile crypt involvement by CIN3, the crypt outline (white arrow) becomes rounded and usually enlarged beyond the normal shape of the crypt ( $\times 4$ magnification, H\&E staining).

cytology testing at follow-up. Cytology recurrence was determined at the time intervals of 6 months, 12 months, and then yearly thereafter. The cytology data of women before and after cold coagulation were obtained from the unit's colposcopy and cytology databases. The cytology follow-up of women was done mainly in primary care settings in accordance to the NHS-CSP guidelines.

Other data that we recorded involved the patient demographics (age, parity, smoking at the time of ablation), referral cytology test results (negative, low grade = borderline nuclear changes in squamous cells or mild dyskaryosis, high grade = moderate or severe dyskaryosis), pretreatment cervical punch biopsy features (number, maximum depth, expansile/non-expansile ECI, histopathology: normal, low-grade histopathology: CIN1, high-grade histopathology: CIN2-3) and pretreatment colposcopic appearance (normal, HPV/inflammation/benign, low-grade, high-grade).

Cold coagulation treatment was performed by British Society for Colposcopy and Cervical Pathology (BSCCP) accredited colposcopists. The requirements set out by the national guidelines for ablative treatment were applied and cold coagulation was offered to women with no suspicion of invasive disease on examination and all women had pretreatment cervical punch biopsy prior to ablation [15]. The Semm cold coagulator (WISAP company, model no. 60001; Brunnthal, Munich, Germany) was applied to the cervix with a minimum temperature of $110^{\circ} \mathrm{C}$ and maximum of $120^{\circ} \mathrm{C}$. The probe application lasted for a minimum of 20 seconds with a minimum of one application and a maximum of four applications. Prior to treatment the cervix was infiltrated with local anaesthetic using 1-3 vials (Citanest $3 \%$ with Octapressin, $2.2 \mathrm{ml}$ vials) to provide comfort and analgesia to women.

\section{Histopathology examination}

The cervical tissue specimens obtained through the pretreatment cervical punch biopsies were sent to the histopathology department for processing and examination. The cervical tissue specimens underwent histopathological examination (JW) and the presence or not of expansile ECI by CIN was noted. The NHS-CSP guidance reports on the entity of expansile CIN3 as CIN3 that extensively involves the endocervical crypts, leading to expansion of the crypts beyond their normal outline. They comment on central necrosis within the affected crypts, which may be seen along with intraepithelial squamous maturation [14]. Expansile endocervical crypt involvement is usually only seen in high grade CIN. The NHS-CSP guidance limits the description to CIN3, however in our study we used the term "expansile endocervical crypt involvement" for cases of CIN2 or CIN3 that extended into and expanded the crypts. $>$ Fig. 1 shows the histopathological features of expansile and non-expansile endocervical crypt involvement by CIN3.

\section{Statistical analysis}

Quantitative variables were expressed as mean values (SD standard deviation) and median values (IQR interquartile range) and qualitative variables were expressed as absolute and relative frequencies. For the comparison of proportions chi-square tests and Fisher's exact tests were used. Mann-Whitney test was used for the comparison of continuous variables between two groups when the distribution was not normal. Kaplan-Meier estimates for events were graphed over the follow-up period. Multivariate Cox regression analysis was used in order to determine if high grade and overall cytology recurrence was associated with the presence of expansile ECl after adjusting for age, smoking, parity, histopathology of pretreatment cervical punch biopsy, number of biopsies and depth of biopsies. Hazard ratios (HR) with 95\% con- 
- Table 1 Sample characteristics for women with and without expansile crypt involvement.

\begin{tabular}{|c|c|c|c|c|}
\hline & & \multicolumn{2}{|c|}{ Expansile crypt involvement } & \multirow[t]{2}{*}{$\mathbf{p}$} \\
\hline & & $\begin{array}{l}\text { No } \\
\text { N (\%) }\end{array}$ & $\begin{array}{l}\text { Yes } \\
\text { N (\%) }\end{array}$ & \\
\hline \multicolumn{2}{|c|}{ Age at the time of treatment, mean (SD) } & $28.7(6.3)$ & $27.9(5.8)$ & $0.508^{\ddagger}$ \\
\hline \multirow[t]{2}{*}{ Smoking at the time of treatment } & No & $300(94.6)$ & $17(5.4)$ & $0.650^{+}$ \\
\hline & Yes & $162(93.6)$ & $11(6.4)$ & \\
\hline \multicolumn{2}{|l|}{ Parity, median (IQR) } & $0(0-1)$ & $0(0-0)$ & $0.015^{\text {tł }}$ \\
\hline \multirow[t]{3}{*}{ Parity } & 0 & $369(93.2)$ & $27(6.8)$ & $0.057^{++}$ \\
\hline & 1 & $74(97.4)$ & $2(2.6)$ & \\
\hline & $\geq 2$ & $86(98.9)$ & $1(1.1)$ & \\
\hline \multirow[t]{3}{*}{ Referral cytology } & Negative & $25(96.2)$ & $1(3.8)$ & $0.053^{+}$ \\
\hline & Low grade & $236(97.1)$ & $7(2.9)$ & \\
\hline & High grade & $268(92.4)$ & $22(7.6)$ & \\
\hline \multirow[t]{2}{*}{ Referral cytology } & Negative/low grade & $261(97.0)$ & $8(3.0)$ & $0.016^{+}$ \\
\hline & High grade & $268(92.4)$ & $22(7.6)$ & \\
\hline \multirow{3}{*}{$\begin{array}{l}\text { Histology of pretreatment cervical } \\
\text { punch biopsies }\end{array}$} & CIN1 & $157(100.0)$ & $0(0.0)$ & $<0.001^{+}$ \\
\hline & CIN2 & $250(47.3)$ & $10(33.3)$ & \\
\hline & CIN3 & $122(23.1)$ & $20(66.7)$ & \\
\hline \multicolumn{2}{|c|}{ Number of pretreatment cervical punch biopsies, mean (SD) } & $1.9(0.9)$ & $1.9(0.8)$ & $0.988^{\ddagger}$ \\
\hline \multicolumn{2}{|c|}{ Maximum depth of pretreatment cervical punch biopsies (mm), mean (SD) } & $3.8(1.3)$ & $4.6(1.9)$ & $0.001^{\ddagger}$ \\
\hline \multirow[t]{4}{*}{ Colposcopy image } & Normal & $3(100.0)$ & $0(0.0)$ & $0.005^{++}$ \\
\hline & HPV/inflam/benign & $76(98.7)$ & $1(1.3)$ & \\
\hline & Low grade & $205(97.6)$ & $5(2.4)$ & \\
\hline & High grade & $223(91.0)$ & $22(9.0)$ & \\
\hline \multirow[t]{3}{*}{ Colposcopy image } & Normal/HPV/inflam/benign & $79(98.8)$ & $1(1.3)$ & $0.002^{+}$ \\
\hline & Low grade & $205(97.6)$ & $5(2.4)$ & \\
\hline & High grade & $223(91)$ & $22(9)$ & \\
\hline
\end{tabular}

fidence intervals $(95 \% \mathrm{Cl})$ were computed from the results of the Cox regression analyses. Life table analyses were used to calculate cumulative cytology recurrence free rates (SE-standard error) for specific time intervals. Maximum depth of biopsies was tested for its ability to detect expansile crypt involvement using receiver operating characteristic (ROC) curves. The overall performance of the ROC analysis was quantified by computing the area under the curve (AUC). An area of 1 indicated perfect performance while 0.5 indicated a performance that was not different than chance. Using ROC analysis we determined the optimal sensitivity and specificity of using various cut-off values for the prediction of expansile crypt involvement. A multiple logistic regression analysis was performed to identify independent associated factors with expansile $\mathrm{ECl}$. Adjusted odds ratios with $95 \%$ confidence intervals were computed from the results of the logistic regression analyses. Model diagnostics were evaluated using the Hosmer and Lemeshow statistic. All reported p-values were two-tailed. Statistical significance was set at $p<0.05$ and analyses were conducted using SPSS statistical software (version 22.0).

\section{Results}

\section{Study group descriptives}

The total sample consisted of 559 women with a mean age of 28.7 years ( $S D=6.2$ years). Non-expansile $\mathrm{ECI}$ was recorded in 24 cases (4.3\%) and expansile endocervical crypt involvement was found in 30 cases $(5.4 \%)$. The sample characteristics for cases with and without expansile $\mathrm{ECl}$ are presented in $>$ Table 1 . Women with expansile ECI when compared with those without had a lower parity and a higher percentage of high grade referral cytology, high grade histology of pretreatment biopsy, high grade colposcopy image, and a greater mean maximum depth of biopsies.

\section{Overall and high grade cytology recurrence of women at follow-up}

Over the entire study period, the proportion of women with overall cytology recurrence was $20 \%$ (6/30) for those with expansile $\mathrm{ECl}$ and $22.1 \%(117 / 529)$ for those without expansile ECI. Also, the proportion of women with high grade cytology recurrence 


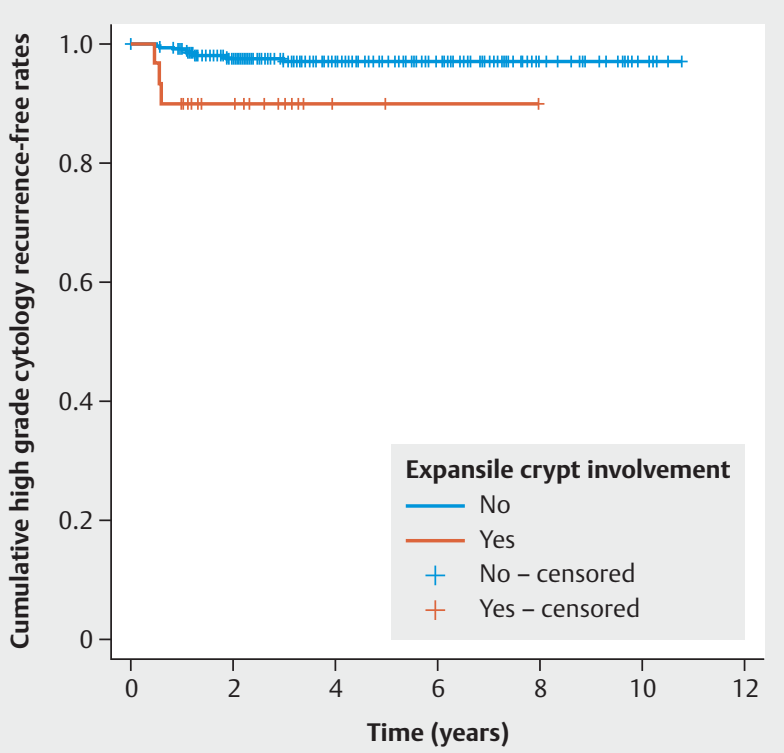

- Fig. 2 Kaplan-Meier estimates for high grade cytology recurrence free rates according to the presence of expansile crypt involvement by CIN2-3 on pretreatment cervical punch biopsies $(p=0.006)$.

was $10 \%$ (3/27) for those with expansile $\mathrm{ECl}$ and $2.3 \%$ (12/517) for those without expansile $\mathrm{ECI}$. The mean follow-up period was 3.2 years $(S D=2.4)$ with a median equal to 2.2 years $(I Q R=1.2-$ 4.4) for those without expansile crypt involvement, while the mean follow-up period was 2.4 years $(S D=1.9)$ with a median equal to 1.7 years $(\mathrm{IQR}=1.0-3.1)$ for those with expansile $\mathrm{ECl}$ (data not shown).

For women without expansile ECI the cumulative overall cytology recurrence-free rate for the first six months was $97 \%$ ( $\mathrm{SE}=1.0 \%$ ) and for one year $85 \%(\mathrm{SE}=2.0 \%)$, while for patients with expansile $\mathrm{ECI}$ the cumulative overall cytology recurrence-free rates for the first six months was $97 \%(\mathrm{SE}=3 \%)$ and for one year $83 \%(\mathrm{SE}=7 \%$ ). For patients without expansile $\mathrm{ECI}$ the cumulative high grade cytology recurrence-free rate for the first six months was $98 \%(\mathrm{SE}=1.0 \%)$ and for one year $92 \%(\mathrm{SE}=0.1 \%)$, while for patients with expansile $\mathrm{ECl}$ the cumulative high grade cytology re-

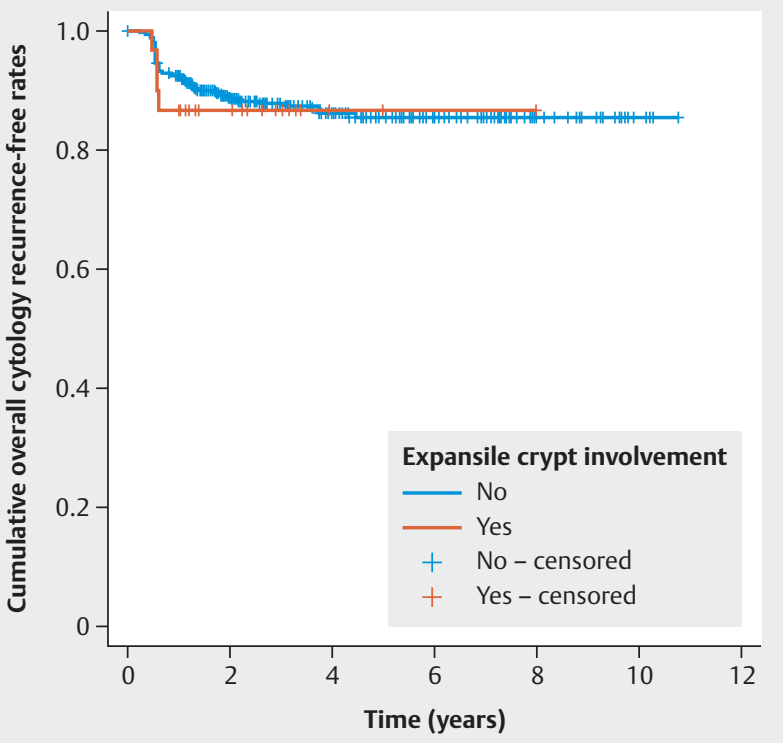

- Fig. 3 Kaplan-Meier estimates for overall cytology recurrence free rates according to the presence of expansile crypt involvement by CIN2-3 on pretreatment cervical punch biopsies $(p=0.682)$.

currence-free rates for the first six months was $97 \%$ (SE $=3 \%$ ) and for one year $86 \%$ (SE $=6 \%)$.

\section{Expansile $\mathrm{ECl}$ as a risk factor for cytology recurrence}

Both univariate and multiple Cox regression analysis ( $>$ Table 2) showed that women with expansile $\mathrm{ECl}$ had a greater hazard for high grade but not overall cytology recurrence ( $\vee$ Figs. 2 and 3 ). Women with expansile ECI had a 4.22 times greater risk for high grade cytology recurrence $(\mathrm{HR}=4.22,95 \% \mathrm{Cl}$ : 1.10-16.29, $\mathrm{p}=0.036$ ) after adjusting for age, smoking, parity, histopathology of pretreatment cervical punch biopsy, number of biopsies and depth of biopsies. When non-expansile ECI was examined no significant association with overall $(\mathrm{HR}=1.54,95 \% \mathrm{Cl}: 0.56-4.26$, $\mathrm{p}=0.400)$ or high grade cytology recurrence $(\mathrm{HR}=2.03,95 \% \mathrm{Cl}$ : $0.26-15.73, p=0.498$ ) was found.

- Table 2 Results from Cox regression analysis for the association of high grade and overall cytology recurrence with the presence of expansile crypt involvement.

\begin{tabular}{|c|c|c|c|c|c|}
\hline & & HR $(95 \% \mathrm{Cl})^{+}$ & $\mathbf{p}$ & HR $(95 \% \mathrm{CI})^{++}$ & $\mathbf{p}$ \\
\hline \multirow{2}{*}{$\begin{array}{l}\text { Overall cytology recurrence } \\
\text { Expansile crypt involvement }\end{array}$} & No (reference) & & & & \\
\hline & Yes & $1.24(0.45-3.39)$ & 0.683 & $1.44(0.50-4.09)$ & 0.498 \\
\hline \multirow{2}{*}{$\begin{array}{l}\text { High grade cytology recurrence } \\
\text { Expansile crypt involvement }\end{array}$} & No (reference) & & & & \\
\hline & Yes & $4.94(1.39-17.52)$ & 0.013 & $4.22(1.10-16.29)$ & 0.036 \\
\hline
\end{tabular}




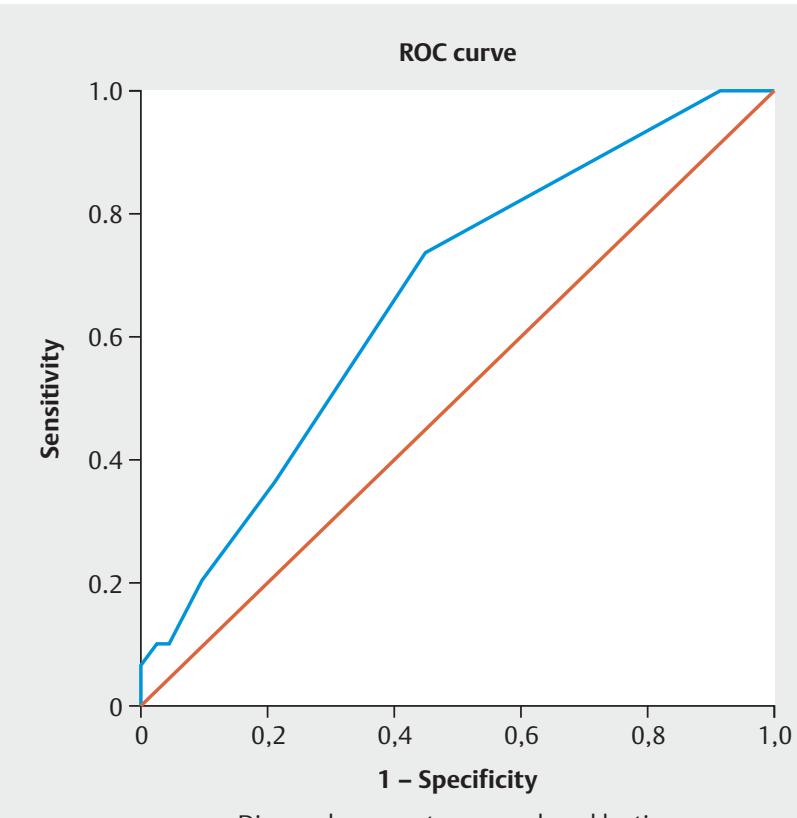

Diagonal segments are produced by ties.

- Fig. 4 ROC analysis for the prediction of expansile crypt involvement by CIN2-3 from the maximum depth of pretreatment cervical punch biopsies.

\section{Predictors for detection of expansile ECI}

Multiple logistic regression analysis with dependent variable that of expansile $\mathrm{ECl}$ ( $\triangleright$ Table 3 ) showed that the increased maximum depth of pretreatment cervical punch biopsies and CIN3 histopathology result on biopsy were significantly associated with greater odds for detecting expansile $\mathrm{ECl}$. ROC curve analysis for the maximum depth of punch biopsies demonstrated that the optimal-cut off for the detection of expansile $\mathrm{ECl}$ was $4 \mathrm{~mm}$ with a sensitivity equal to $73.3 \%$ and a specificity equal to $55.1 \%$. The area under the curve (AUC) was $0.66(95 \% \mathrm{Cl}: 0.57-0.75)$, which significantly differs from $0.5(p=0.003)$ ( $\triangleright$ Fig. 4).

\section{Discussion}

In our study we detected endocervical crypt involvement by CIN2-3 on pretreatment cervical punch biopsies in a total of 54 (9.7\%) women treated with cold coagulation, of which non-expansile $\mathrm{ECl}$ involved 24 cases (4.3\%) and expansile ECI 30 cases (5.4\%). Comparable rates of overall endocervical crypt involvement by CIN2-3 on cervical tissue histopathology have been reported in the literature for excisional cervical treatment ranging from 15 to $58 \%[10-12,16]$. In our cohort of women being treated with cold coagulation, expansile crypt involvement by CIN2-3 represented more than half of the cases of crypt involvement (55.5\% or $30 / 54)$, and was associated with CIN2 in one third (33.3\% or $10 / 30$ ) and with CIN3 in two thirds $(66.7 \%$ or $20 / 30$ ) of women with expansile $\mathrm{ECl}$. On review of the literature, even though the NHS-CSP guidance on crypt involvement reporting was issued in 2012, we could not identify any studies reporting on the rates of expansile crypt involvement by CIN3 in women being treated for cervical precancerous lesions. Moreover, the NHS-CSP guidance reports only on the entity of expansile CIN3, whereas in our study one in three women with expansile crypt involvement had CIN2 lesions.

Our initial study in 2015 that involved the same cohort of 559 women who were treated with cold coagulation demonstrated that the only significant risk factor for high grade cytology recurrence at follow-up was the presence of $\mathrm{ECl}$ on pretreatment cervical punch biopsies $(\mathrm{HR}=3.72,95 \% \mathrm{Cl}$ : 1.18-11.71; $\mathrm{p}=0.024$ ) [8]. With this secondary analysis we found that approximately $55.5 \%$ of women with $\mathrm{ECI}$ had essentially expansile ECI. We have shown that these women with expansile ECI had a 4.22 times greater risk for high grade cytology recurrence $(H R=4.22$, 95\% Cl: 1.10-16.29; $p=0.036)$. When non-expansile $E C l$ was examined there was no significant association with high grade cytology recurrence $(\mathrm{HR}=2.03,95 \% \mathrm{Cl}: 0.26-15.73, \mathrm{p}=0.498)$. On review of the literature, we have not identified any similar study in-

- Table 3 Results from logistic regression analysis to identify independent associated factors with the presence of expansile crypt involvement.

\begin{tabular}{|l|l|l|}
\hline & & OR (95\% CI)+ \\
\hline Age (years) & & $1.01(0.94-1.09)$ \\
\hline Parity & 0 (reference) & 0.714 \\
\hline & 1 & $0.32(0.07-1.42)$ \\
\hline Smoking at the time of treatment & $\geq 2$ & $0.20(0.03-1.56)$ \\
\hline & No (reference) & 0.135 \\
\hline Number of pretreatment cervical punch biopsies & Yes & $1.08(0.59-1.97)$ \\
\hline Maximum depth of pretreatment cervical punch biopsies & & $0.91(0.57-1.45)$ \\
\hline Histopathology of pretreatment cervical punch biopsy & & $1.34(1.08-1.66)$ \\
\hline
\end{tabular}


dicating that when endocervical crypt involvement is reported on cervical tissue histopathology from pretreatment cervical punch biopsies, then the chances of expansile $\mathrm{ECl}$ are more than $50 \%$ and this increases by four-fold the likelihood of high grade cytology recurrence after cold coagulation.

Given the fact that endocervical crypts extend to a maximum depth of $5 \mathrm{~mm}$ from the surface of the cervix [17 - 19], in order to increase the detection rate of expansile ECI when planning for cold coagulation treatment then deeper pretreatment punch biopsies need to be obtained. We have shown that the increasing depth of pretreatment cervical punch biopsies was significantly associated with greater odds for the detection of expansile $\mathrm{ECI}$, with the optimal-cut off for the detection of expansile crypt involvement being the depth of $4 \mathrm{~mm}$ with a sensitivity of $73.3 \%$. Nevertheless, a punch biopsy with a depth of $4 \mathrm{~mm}$ or more may not always be feasible to obtain such as in cases of obesity with difficult colposcopic access to the uterine cervix.

\section{Limitations - strengths}

Our study has certain limitations to consider. First, this was a secondary analysis on a previous study [8] with retrospective collection of data and therefore it represents a level 3 of evidence in the published literature [20]. Second, the presence or not of expansile $\mathrm{ECl}$ involvement by CIN2-3 was assessed by a single histopathologist (JW). According to the NHS-CSP guidance as to the definition of expansile CIN3 [14], there seems to be an inevitable degree of subjectivity when assessing the extent of crypt involvement and when evaluating the expansion of the underlying crypts. Nevertheless, we expect that the bias that is introduced to be of limited magnitude since all histopathologists working in the United Kingdom are routinely being subjected to national histopathology quality assurance. Third, we recorded the cytology-only recurrence at the follow-up of the 559 women who were treated with cold coagulation. The HPV test of cure had not been introduced within our Trust until after our data collection was completed. Finally, the smoking status was available for women only at the time-point of cold coagulation treatment and not during their follow-up. For this reason, we were not able to adjust for smoking as a confounding factor at follow-up when assessing the cytology recurrence after treatment.

The main strength of our study was its sample size and the high compliance of women in attending their follow-up cytology tests after cold coagulation. Follow-up data within 6 and 12 months from treatment were available for 92.3 and $90.3 \%$ of women which is in accordance with other published studies with larger sample sizes [21, 22].

\section{Conclusion}

Our study has shown that expansile ECI on pretreatment cervical punch biopsies is a risk factor for high grade cytology recurrence after cold coagulation treatment. We have shown that deeper cervical punch biopsies at a depth greater than $4 \mathrm{~mm}$ should be obtained prior to treatment with cold coagulation so as to increase the detection rate of expansile crypt involvement. It is unclear at the moment whether these women with expansile crypt involvement by CIN2-3 should be offered more extensive ablative treat- ment with the cold coagulator or whether they should have cervical excision. Further research is needed with large prospective studies to clarify whether cold coagulation should be reserved only for young women of reproductive age with non-expansile crypt involvement by CIN2-3 on pretreatment cervical punch biopsies.

\section{Acknowledgements}

We would like to thank Mrs. Tzavara Chara, biostatistician from the Department of Hygiene, Epidemiology and Medical Statistics, at the Medical School of University of Athens in Greece for her support in conducting the statistical analyses of data.

\section{Conflict of Interest}

The authors declare that they have no conflict of interest.

\section{References}

[1] Semm K. New apparatus for the 'cold-coagulation' of benign cervical lesions. Am J Obstet Gynecol 1966; 95: 963-966

[2] O’Dwyer V, Madden M, Hickey K. Cold coagulation to treat cervical intraepithelial neoplasia. BJOG 2013; 120: 510

[3] Papoutsis D, Underwood M, Parry-Smith W et al. Comparison of cure rates in women treated with cold-coagulation versus LLETZ cervical treatment for CIN2-3 on pretreatment cervical punch biopsies: a retrospective cohort study. Arch Gynecol Obstet 2017; 295: 979-986

[4] Dolman L, Sauvaget C, Muwonge R et al. Meta-analysis of the efficacy of cold coagulation as a treatment method for cervical intraepithelial neoplasia: a systematic review. BJOG 2014; 121: 929-942

[5] Randall TC, Sauvaget C, Muwonge R et al. Worthy of further consideration: An updated meta-analysis to address the feasibility, acceptability, safety and efficacy of thermal ablation in the treatment of cervical cancer precursor lesions. Prev Med 2019; 118: 81-91

[6] Tadesse WG, Oni AAA, Hickey KPW. Effectiveness of cold coagulation in treating high-grade cervical intraepithelial neoplasia: the human papillomavirus evidence of cure. J Obstet Gynaecol 2019; 39: 965-968

[7] Papoutsis D, Underwood M, Parry-Smith W et al. Early and late pregnancy outcomes in women treated with cold-coagulation versus LLETZ cervical treatment for cervical intraepithelial neoplasia; a retrospective cohort study. Arch Gynecol Obstet 2018; 297: 1015-1025

[8] Papoutsis D, Underwood M, Parry-Smith W et al. Risk factors for treatment failure following cold coagulation cervical treatment for CIN pathology: a cohort-based study. Arch Gynecol Obstet 2015; 292: 13291337

[9] Papoutsis D, Panikkar J, Underwood M et al. Endocervical Crypt Involvement by CIN2-3 as a Predictor of Cytology Recurrence After Excisional Cervical Treatment. J Low Genit Tract Dis 2015; 19: 311-318

[10] Meng QW, Qn ZH, Mao Y et al. [Prognostic factors of cervical high-grade squamous intraepithelial lesions treated by cold knife conisation with negative margin]. Zhonghua Fu Chan Ke Za Zhi 2007; 42: 457-459

[11] Livasy CA, Maygarden SJ, Rajaratnam CT et al. Predictors of recurrent dysplasia after a cervical loop electrocautery excision procedure for CIN-3: A study of margin, endocervical gland, and quadrant involvement. Mod Pathol 1999; 12: 233-238

[12] Demopoulos RI, Horowitz LF, Vamvakas EC. Endocervical gland involvement by cervical intraepithelial neoplasia grade III. Predictive value for residual and/or recurrent disease. Cancer 1991; 68: 1932-1936 
[13] Rasbridge SA, Jenkins D, Tay SK. A histological and immunohistological study of cervical intraepithelial neoplasia in relation to recurrence after local treatment. Br J Obstet Gynaecol 1990; 97: 245-250

[14] NHS cervical screening programme. Histopathology Reporting in cervical Screening-an integrated Approach. 2nd ed. Sheffield, England: NHSCSP Publication No. 10; 2012

[15] Luesley D, Leeson S. Colposcopy and Programme Management. Guidelines for the NHS cervical screening programme. 2nd ed. Sheffield, England: NHSCSP Publication No. 20; 2010

[16] Kodampur M, Kopeika J, Mehra G et al. Endocervical crypt involvement by high-grade cervical intraepithelial neoplasia after large loop excision of transformation zone: do we need a different follow-up strategy? J Obstet Gynaecol Res 2013; 39: 280-286

[17] Boonstra H, Aalders JG, Koudstaal J et al. Minimum extension and appropriate topographic position of tissue destruction for treatment of cervical intraepithelial neoplasia. Obstet Gynecol 1990; 75: 227-231
[18] Anderson MC, Hartley RB. Cervical crypt involvement by intraepithelial neoplasia. Obstet Gynecol 1980; 55: 546-550

[19] Byrom J, Douce G, Jones PW et al. Should punch biopsies be used when high-grade disease is suspected at initial colposcopic assessment? A prospective study. Int J Gynecol Cancer 2006; 16: 253-256

[20] Phillips B, Ball C, Sackett D et al. Oxford Centre for evidence-based medicine levels of evidence, 2009. Online: http://www.cebm.net/oxfordcentre-evidence-based medicine-levels-evidence-march-2009; last access: 28.12 .2019

[21] Kitchener HC, Walker PG, Nelson L et al. HPV testing as an adjunct to cytology in the follow up of women treated for cervical intraepithelial neoplasia. BJOG 2008; 115: 1001-1007

[22] van Hamont D, van Ham MA, Struik-van der Zanden PH et al. Long-term follow-up after large-loop excision of the transformation zone: Evaluation of 22 years treatment of high-grade cervical intraepithelial neoplasia. Int J Gynecol Cancer 2006; 16: 615-619 